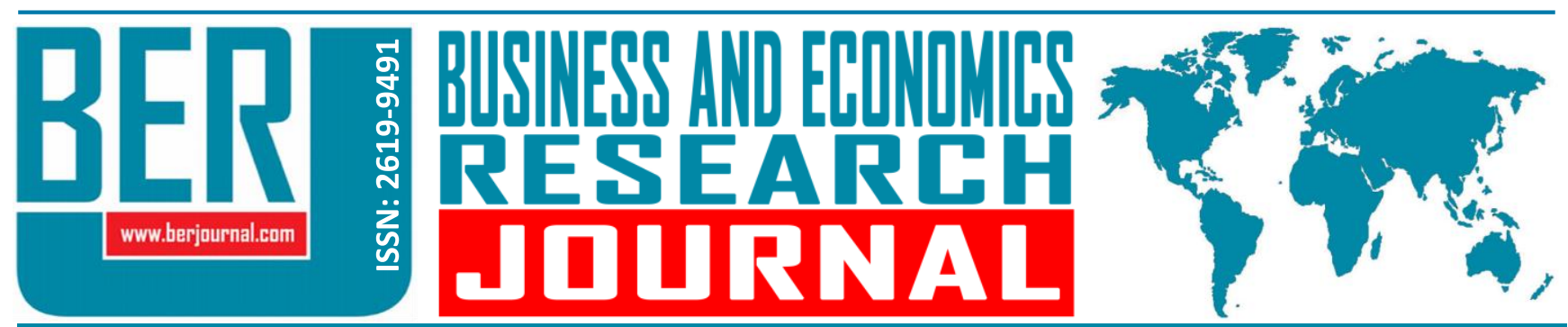

Business and Economics Research Journal Vol. 10, No. 2, 2019, pp. 405-414 doi: 10.20409/berj.2019.176

\section{STAR Modelleri: Kişi Başına GSYİH Büyüme Hızı İçin Bir Uygulama}

\section{Fatma Idil Baktemur}

Öz: Doğrusallık varsayımı uzun süre geçerli olmuştur ancak iktisadi zaman serilerinin çoğu asimetrik davranışlar sergilemektedir. Hesaplama güçlüklerinin kaldırılmasıyla uygulamada doğrusal olmayan zaman serileri çalışmalarının sayısı artmıştır. Markov rejim değişim modelleri, TAR ve STAR modelleri doğrusal olmayan zaman serileri çalışmalarına örnek verilebilir. Kişi başına GSYiH, iktisadi büyümenin önemli bir unsurudur ve pek çok çalışmaya konu olmuştur. 1961-2017 yıllık verilerini kapsayan bu çalıșma Türkiye için kişi başına GSYiH büyüme hızının doğrusal olmayan yapısını STAR modelleri ile incelemiştir. Seri birim kök testi sonuçlarına göre durağandır ve modelin gecikme uzunluğu iki olarak bulunmuştur. Bağımlı değişkenin gecikmelerine göre tek tek geçiş değişkenleri oluşturulmuş ve modelin doğrusallığı doğrusal olmama alternatifine göre test edilmiştir. Birinci gecikme geçiş değişkeni olarak seçilmiştir. \%5 anlamlılık düzeyinde doğrusallık hipotezi reddedilmiştir. Çalışmanın bulguları büyüme için LSTAR tipi modellemenin uygun olduğunu göstermektedir. Uygun model LSTAR olduğu için geçiş değişkeni standart hatasına bölünerek standartlaştırılmıştır. Geçiş yumuşaklığını gösteren parametre bir rejimden diğer rejime geçişin hızlı olduğunu göstermektedir.

\section{STAR Models: An Application for GDP Per Capita Growth Rate}

Abstract: The linearity assumption has been valid for a long time but most of the economic time series exhibit asymmetric behavior. The number of studies of nonlinear time series studies have increased in application by removing calculation difficulties. Markov regime switching models, TAR and STAR models are examples of nonlinear time series studies. GDP per capita is an important element of economical growth and has been the subject of many studies. This study covering the annual 1961-2017 data examined the nonlinear structure of GDP per capita growth rate for Turkey with STAR models. The serie is stationary according to the unit root test results and the delay length of the model has been found as two. Transition variables has been created by the delays of the dependent variable one by one and the linearity of the model has been tested against its nonlinearity alternative. The first delay has been selected as the transition variable. At the level of significance of 5\%, the linearity hypothesis has been rejected. Findings of the study show that LSTAR model type is appropriate for growth. Since the appropriate model is LSTAR, transition variable has been standardized by its standard error. The parameter indicating the smoothness of transition shows that the transition from one regime to another is quick.
Anahtar Sözcükler: Doğrusal Olmama, GSYIH, Büyüme, STAR Modelleri, Rejim Geçişi

JEL: C24, C01, C22

Geliş : : 08 Kasım 2018

Düzeltme : 26 Kasım 2018

Kabul : 09 Ocak 2019

Tür : : Araştırma

Keywords: Nonlinear, GDP, Growth, STAR Models, Regime Switching

JEL: C24, C01, C22

Received : 08 November 2018 Revised : 26 November 2018 Accepted : 09 January 2019

Type : Research 


\section{Giriş}

Ekonomik büyüme mal ve hizmet üretim kapasitesindeki genişleme olarak tanımlanabilir ve reel gayri safi yurtiçi hasıladaki (GSYiH) artış olarak ölçülmektedir (Parasız, 2008: 10). Kişi başına GSYiH, yaşam standardının bir ölçüsüdür. Bir ülkenin kişi başına GSYiH'sının zaman içindeki değiş̧imi, ülkenin ekonomik büyümesine ve ülke sakinlerinin yaşam standartlarının gelişip gelişmediğine işaret eder (Schein, 2013: 973).

Rostow'a (1960) göre büyümenin aşamaları 5 başlıkta özetlenebilir. Bunlar geleneksel toplum aşaması, kalkışa hazırlık, kalkış, olgunluk ve kitle tüketimidir. Birinci aşamada toplam üretimde tarımsal ürünlerin ağırlığı fazladır ve teknoloji ilkeldir. Kişi başına gelir de düşük seviyededir. Ekonomik büyüme de sınırlı seviyededir. İkinci aşamada büyüme için başlangıç koşulları hazırlanmaktadır. Tarımda yeni teknikler gelişmekte, gelişmiş ülkelerin etkisiyle eğitim düzeyi yükselmekte ve banka gibi kurumlar kurulmaktadır. Üçüncü aşamada toplum kendi düzenli büyümesine karşı koyan engelleri kaldırmaktadır. Yeni endüstriler gelişmekte ve bu süreç geri kalan ekonomi üzerinde sürükleyici bir etki yaratmaktadır. 20-30 yıl sürdüğü belirtilmektedir. Dördüncü aşama kalkışın sona ermesinden 40 yıl sonra başlamaktadır. Yeni teknolojiler yeni endüstrilerin gelişmesine izin verirken, diğer sektörler bazı güçlüklerle karşılaşmaktadır. Ekonomi yıkmayaratma sürecine girmekte ve kalkınma düzenli bir olgu olmaktadır. Son aşamada dayanıklı tüketim malları üretimi gelişmekte ve ekonomik büyümede hizmetler rol oynamaya başlamaktadır (Parasız, 2008: 80-81).

Ekonominin büyüme yolu başlangıçta bir durgunluk gösterir, kalkış aşamasında büyüme oranları artar ve sonunda istikrarlı bir büyüme rejimine ulaşılır (Fiaschi ve Lavezzi, 2007: 271).

İktisat literatüründe büyüme modelleri iki alt başlıkta incelenmektedir. Bunlardan dışsal büyüme modelleri büyümeyi ve teknolojik değişmeyi dışsal kabul etmektedir(Parasız, 2008: 131). Dışsal büyüme modelleri zamanla eleştirilmiş ve içsel büyüme modelleri geliştirilmiştir. Bu modeller sermayenin azalan getirisi olmadığını ifade etmektedir (Parasız, 2008: 169). Bilgi ve beşeri sermaye vurgulanmıştır (Parasız, 2008: 175).

Bilindiği gibi zaman serisi analizlerinde doğrusal olmayan yaklaşımlar son zamanlarda gelişmiş ekonometrik programlar ile artmıştır. Doğrusal olmayan zaman serileri analizi klasik doğrusal tekniklerle çözümlenemeyen bilgiyi elde etmeye imkan sağlar (Andrzejak, 2011: 125).

îktisatta konjonktürel dalgalanmalar ilk olarak Jevons'un güneş lekeleri yaklaşımı ile açıklanmıştır. Güneş lekelerinin tarımsal ürünlerin verimliliğini ve fiyatlarını etkilediği belirtilmiştir. Ürün fiyatlarındaki bu değişimler de ekonomik krizlere yol açmaktadır (Bildirici vd., 2010: 12).

İşsizlik oranı ve GSYiH'nın büyüme oranı gibi konjonktürel değişkenlerin iş çevrimi döngülerinin çeşitli evrelerinde asimetrik davranışlar gösterdiği her zaman tartışımıştır. Çoğu iktisatçı döngünün üst evresinin alt evresinden daha uzun olduğunu gözlemlemiştir (Kunitomo ve Sato, 1996: 2).

Zaman serisi analizlerinde asimetrik yapıyı, yani doğrusal olmama durumunu Neftçi (1984) ve Hamilton (1989) çalışmalarında ele almışlardır. Reel üretim ve işsizlik oranı gibi makroekonomik serilerin süreçlerini tanımlamada doğrusal modellerin yeterli olamayacaklarını ifade etmişlerdir. Neftçi (1984) ikinci dereceden bir Markov zincirini kullandığı çalışmasında, ABD’nin işsizlik oranının asimetrik davranışlar gösterdiğini bulmuştur. Hamilton (1989) ise, ABD'nin GSMH büyüme hızının genişleme ve daralma dönemlerinde gösterdiği asimetriyi birinci dereceden bir Markov zinciri ile modellemiştir (Bildirici vd., 2010: 19-20). Bu çalışmalar zaman serisi analizlerinde doğrusal olmayan yapıyı ele alan öncü çalışmalardır ve daha sonraki çalışmaları da etkilemiştir. Terasvirta ve Anderson (1992) sanayi üretim endeksi büyüme hızını ABD, Kanada, Belçika, İtalya, Almanya ve Japonya için STAR modelleri ile analiz etmişlerdir.

Büyümenin doğrusal olmayan yapısı uzun süreden beri çalışılmaktadır. Peretto (1999) doğrusal olmayan büyüme sürecinin sermaye birikiminin yarattığı büyümeden, ölçeğe dönüşün azalmasıyla, bilgi birikimine dayalı büyümeye geçişin bir sonucu olduğunu ileri sürmektedir. Nejad vd. (2005) ekonomik gelişimin doğrusal biçimde gerçekleşmediğini vurgulamaktadır. Ekonomik büyüme yolundaki sıçramalar ve doğrusal olmama çalışmalarında ele alınmıştır. Kalaitzidakis vd. (2001) ise beşeri sermayenin büyüme üzerindeki etkisinin doğrusal olmadığını ifade etmişlerdir. 
Literatürde büyümenin doğrusal olmayan yapısını inceleyen başka çalışmalar da vardır. Burren ve Neusser (2010) ABD için kişi başına GSYiH büyüme hızının volatilitesini incelemişlerdir. Mills (1995a) İngiltere için GSYiH'nın doğrusal olmayan yapısını inceleyenlerden biridir. Öcal (2000) İngiltere için bazı makroekonomik serilerdeki asimetrikliği incelemiştir. Kişi başına GSYiH büyüme hızını modellemede STAR modelleri kullanılmıştır. Öcal (2006) çalışmasında da STAR modellerini tercih etmiştir. BouAli, Nasr ve Trabelsi (2016) ABD'de GSYiH büyüme hızını Markov ve STAR modelleri ile incelemeyi tercih etmişlerdir. Potter (1993) ABD için GSMH'yı SETAR modeli ile incelemiş ve asimetrik etkileri ortaya koymuştur. Fiaschi ve Lavezzi (2003) büyümenin doğrusal olmayan yapısını ve yakınsamayı kişi başına nispi geliri kullanarak incelemişlerdir. Fiaschi ve Lavezzi (2007) çalışmalarında bir ülkenin kendi gelişim süreciyle ilgili olası doğrusal olmayan dinamikleri tespit etmeyi hedeflemişlerdir. Bir önceki çalışmalarından farklı olarak kişi başına mutlak geliri kullanmışlar ve Markov geçiş matrisi ile büyümenin yapısının doğrusal olmadı̆̆ını belirtmişlerdir. Pede vd. (2008) ABD için büyümeyi incelediği çalışmasında STAR modellerini mekansal analize dahil etmişlerdir. Florax vd. (2009) ABD için ekonomik büyümeyi mekansal analiz ve STAR modellerini birleştirerek modellemişlerdir. Türkiye için yapılan çalışmalara bakıldığında Akgül ve Özdemir (2012) enflasyon büyüme ilişkisini TAR modeli ile, Karaduman (2007) enflasyon büyüme ilişkisini STAR modeli ile incelemişlerdir. Bayramoğlu ve Yurtkur (2016) karbon emisyonu ve ekonomik büyüme ilişkisini doğrusal olmayan eşbütünleşme yöntemleri ile incelemişlerdir.

Bu çalışmada Türkiye için kişi başına GSYiH büyüme hızının doğrusal olmayan yapısı STAR modelleri ile incelenecektir. Çalışmanın ikinci bölümünde STAR modellerinin ekonometrik altyapısı tartışılmıştır. Üçüncü bölümde uygulamaya yer verilmiştir. Türkiye için 1961-2017 dönemi büyüme verileri kullanılarak doğrusal olmayan model tahmin edilmiştir. Dördüncü bölümde ise sonuçlar tartışılmıştır.

\section{STAR Modeli}

Tek değişkenli zaman serisi $y^{t}$ için STAR modeli Van Dijk vd. (2002) çalışmasında olduğu gibi (1) numaralı denklemde belirtilmiştir:

$$
\begin{aligned}
y_{t} & =\left(\phi_{1,0}+\phi_{1,1} y_{t-1}+\ldots+\phi_{1, p} y_{t-p}\right)\left(1-G\left(s_{t} ; \gamma, c\right)\right)+\left(\phi_{2,0}+\phi_{2,1} y_{t-1}+\ldots+\phi_{2, p} y_{t-p}\right) G\left(s_{t} ; \gamma, c\right)+\varepsilon_{t} \\
\mathrm{t}=1, \ldots, \mathrm{T} & \\
y_{t} & =\left(\phi_{1}^{\prime} x_{t}\left(1-G\left(s_{t} ; \gamma, c\right)\right)+\phi_{2}^{\prime} x_{t} G\left(s_{t} ; \gamma, c\right)+\varepsilon_{t}\right.
\end{aligned}
$$

Geçiş fonksiyonu $G\left(s_{t} ; \gamma, c\right.$ sürekli bir fonksiyondur ve 0 ile 1 arasında değerler almaktadır, bir rejimden diğerine geçiş yumuşak bir şekilde gerçekleşmektedir. Geçiş değişkeni içsel değişkenin gecikmelisi, dışsal bir değişken ve zaman trendi de olabilmektedir. Geçiş fonksiyonu LSTAR ve ESTAR modelleri olarak ikiye ayrılmaktadır.

LSTAR:

$$
G\left(s_{t} ; \gamma, c\right)=\left(1+\exp \left\{-\gamma\left(s_{t}-c\right)\right\}\right)^{-1} \quad \gamma>0
$$

ESTAR:

$$
G\left(s_{t} ; \gamma, c\right)=\left(1-\exp \left\{-\gamma\left(s_{t}-c\right)^{2}\right\} \quad \gamma>0\right.
$$

(3) numaralı model lojistik STAR modelidir. c iki rejim arasındaki eşik değerini, $\gamma$ ise geçiş fonksiyonunun hızını göstermektedir. $\gamma^{\prime}$ nın aldığı büyük değerler hızlı geçişi ifade etmektedir. $\gamma$ sonsuza giderken $(\gamma \rightarrow \infty)$ lojistik fonksiyon 1'e yaklaşır ve LSTAR modeli iki rejimli TAR modeli haline gelir. $\gamma=0$ iken LSTAR modeli doğrusal bir AR modeline indirgenir. İş çevrimi döngülerinin asimetrik yapıSı LSTAR modelleri ile ifade edilebilmektedir. 
(4) numaralı model üssel STAR modelidir. Üssel fonksiyon simetriktir ve 0 etrafında $U$ şeklini alır. ESTAR modeli $\gamma$ 0'a $(\gamma \rightarrow 0)$ ya da sonsuza $(\gamma \rightarrow \infty)$ giderken doğrusal AR modeline dönüşür. Bu modelle reel döviz kuru çalışmalarında karşılaşılmaktadır.

Granger ile Teräsvirta (1993) ve Teräsvirta'nın (1994) çalışmalarında STAR modelinin değerlendirme aşamaları birkaç adımda özetlenmiştir. Buna göre:

a) doğrusal AR modeli seçilir. (Zaman serisinin gecikme yapısı Akaike veya Schwarz kriterleri ile belirlenir.)

b) doğrusallık hipotezi test edilir.

c) doğrusallık reddedilirse uygun geçiş fonksiyonu oluşturulur.

d) model tahmin edilir ve kestirim amacıyla değerlendirilir.

Sıfır hipotezi altında STAR modelindeki parametreler tanımlı olmadığı için, doğrusal hipotezin, alternatifi olan STAR modeline karşı test edilmesi karışık bir durum yaratmaktadır. Luukkonen vd. (1988) ve Teräsvirta'nın (1994) geliştirmiş olduğu testler gecikmeli değerli yardımcı regresyon ((5) numaralı denklem) ile bu sorunu gidermektedir.

$$
y_{t}=\beta_{0}+\sum_{i=1}^{\rho} \beta_{1 i} y_{t-i}+\sum_{i=1}^{\rho} \beta_{2 i} y_{t-i} y_{t-d}+\sum_{i=1}^{\rho} \beta_{3 i} y_{t-i} y_{t-d}^{2}+\sum_{i=1}^{\rho} \beta_{4 i} y_{t-i} y_{t-d}^{3}+\varepsilon_{t}
$$

Doğrusallığın test edilmesi $H_{0}: \beta_{2 i}=\beta_{3 i}=\beta_{4 i}=0 \quad i=1,2, \ldots, \rho$ hipotezinin test edilmesi anlamına gelmektedir. Bu LM testi $3(\rho+1)$ serbestlik dereceli $\chi^{2}$ dağılımına uymaktadır. Doğrusallık d'nin birden fazla değerleri için reddediliyorsa en düşük $\rho$ değerli $\mathrm{d}$ seçilir. Küçük örneklemlerde LM istatistiğinin $\mathrm{F}$

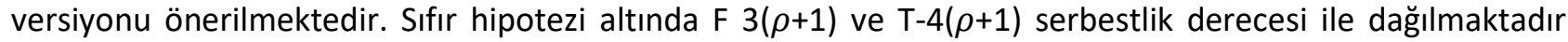
(Camarero ve Ordonez, 2012: 445).

Doğrusallık reddedildiğinde modelin LSTAR mı yoksa ESTAR mı olduğuna karar vermek gerekmektedir. Granger ve Teräsvirta (1993) LSTAR ve ESTAR modelleri arasında seçim yapabilmek için aşağıdaki hipotezleri geliştirmişlerdir:

$$
\begin{aligned}
& H_{03}: \beta_{4 i}=0 i=1,2, \ldots, \rho \\
& H_{02}: \beta_{3 i}=0 / \beta_{4 i}=0 i=1,2, \ldots, \rho \\
& H_{01}: \beta_{2 i}=0 / \beta_{3 i}=\beta_{4 i}=0 i=1,2, \ldots, \rho
\end{aligned}
$$

$H_{02}$ en küçük olasılık değerine sahip ise ESTAR modeli, diğer durumlarda ise LSTAR modeli seçilir. Terasvirta (1994) çalışmasında geçiş değiş̧eninin standartlaştırılıp, ölçekten arındırılması gerektiği belirtilmiştir. Model LSTAR ise geçiş değişkeninin standart hatasına, model ESTAR ise varyansına bölünmelidir.

$$
\begin{array}{ll}
G\left(s_{t} ; \gamma, c\right)=\left(1+\exp \left\{-\gamma\left(s_{t}-c\right)\right\} / \sigma_{s_{t}}\right)^{-1} & \gamma>0 \\
G\left(s_{t} ; \gamma, c\right)=\left(1-\exp \left\{-\gamma\left(s_{t}-c\right)^{2} / \sigma_{s_{t}}^{2}\right\}\right. & \gamma>0
\end{array}
$$

Geçiş fonksiyonu geçiş değişkeninin standart hatası (LSTAR modeli için) ya da varyansıyla (ESTAR modeli için) standardize edildikten sonra $\gamma=1$ uygun bir başlangıç değeri olacaktır. Uygun model yapısına ulaşana kadar $\gamma$ sabit kabul edilir. Sonra $\gamma$ serbest bırakılarak model tahmin edilir. Yakınsama sorunu olmazsa kurulan model yeterlidir (Terasvirta, 1994: 213).

STAR modeli tahmin edildikten sonra $\gamma^{\prime}$ nın değeri ve standart hatası büyük çıkabilmektedir. Bunun nedeni geçiş eşiğinin yakın komşuluğunda çok fazla gözlenen değer olmaması olabilir. STAR modelinin süreci yakalayamadığı şeklinde yorumlanmamalıdır (Bates ve Watts, 1988; Van Dijk vd., 2002). Bu durumda $\gamma^{\prime}$ nın standart hatasını belirtmeye gerek yoktur (Karaduman, 2007: 29). 
Model tahmin edildikten sonra; otokorelasyon ve değişen varyans sorununun olup olmadığı, doğrusal olmayan yapının yeterli olup olmadığı ve parametrelerin zamandan bağımsız olup olmadığı test edilmektedir.

Otokorelasyon testi 3 aşamada gerçekleştirilmektedir (Eitrheim ve Terasvirta, 1996: 61-63):

1. Otokorelasyon olmadığı varsayımıyla STAR modelinin tahmin edilmesi ve hata kareleri toplamının $S S R_{0}=\sum_{t=1}^{T} \hat{u}_{t}^{2}$ hesaplanması

2. $\hat{u}_{t}{ }^{\prime}$ nın yardımcı regresyonunun kurulup hata kareleri toplamının hesaplanması

3. $F_{L M}=\frac{\left(S S R_{0}-S S R\right) / q}{S S R /(T-n-q)}$ hesaplanması

Zaman içinde değişen parametre vektörleri (9), (10) ve (11) numaralı denklemlerde tanımlanmaktadır (Eitrheim ve Terasvirta, 1996: 67-69):

$$
\begin{aligned}
& H_{1}\left(t ; \gamma_{1}, c_{1}\right)=\left(1+\exp \left\{-\gamma_{1}\left(t-c_{1}\right)\right\}\right)^{-1}-0,5 \\
& H_{2}\left(t ; \gamma_{1}, c_{1}\right)=\left(1-\exp \left\{-\gamma_{1}\left(t-c_{1}\right)^{2}\right\}\right. \\
& H_{3}\left(t ; \gamma_{1}, c_{1}\right)=\left(1+\exp \left\{-\gamma_{1}\left(t^{3}+c_{12} t^{2}+c_{11} t+c_{10}\right)\right\}\right)^{-1}-0,5 \\
& \gamma_{1}>0 \\
& c_{1}=\left(c_{10}, c_{11}, c_{12}\right)^{\prime}
\end{aligned}
$$

Sıfır hipotezi parametre sabitliğini ifade etmektedir $\left(H_{0}: \gamma_{1}=0\right)$.

(9) Yumuşak ve monoton parametre değişimini; (10) monoton olmayan parametre değişimini; (11) ise monoton ve monoton olmayan parametre değişimini ifade etmektedir. Bu üç hipotezin test edilebilmesi için birinci dereceden Taylor açılımına ihtiyaç vardır.

Kalan doğrusal olmayanlık testi, nihai modelin veri yaratım sürecindeki doğrusal olmayanlığı kesin olarak modelleyip modellemediğini görebilmek için kullanılmaktadır (Eitrheim ve Terasvirta, 1996: 64-65).

3. dereceden Taylor açılımı ile:

$$
y_{t}=\beta_{0}^{\prime} x_{t}+\left(\phi_{2}-\phi_{1}\right)^{\prime} x_{t} G_{1}\left(s_{t} ; \gamma_{1}, c_{1}\right)+\beta_{1}^{\prime} x_{t} s_{t}+\beta_{2}^{\prime} x_{t} s_{t}^{2}+\beta_{3}^{\prime} x_{t} s_{t}^{3}+e_{t}
$$

(12) numaralı denklem elde edilir.

SIfır hipotez $H_{0}^{\prime}: \beta_{1}=\beta_{2}=\beta_{3}=0$ şeklindedir.

Kapetanios vd. (2003) STAR modellerinde durağanlığı sınamışlardır (Camarero ve Ordonez, 2012: 446):

$$
\begin{aligned}
& y_{t}=\varphi y_{t-1}+\tilde{\varphi} y_{t-1}\left(1-\exp \left\{-\gamma y^{2}{ }_{t-d}\right\}\right)+\varepsilon_{t} \\
& \Delta y_{t}=\beta y_{t-1}+\tilde{\varphi} y_{t-1}\left(1-\exp \left\{-\gamma y^{2}{ }_{t-d}\right\}\right)+\varepsilon_{t}
\end{aligned}
$$

$\beta=\phi-1$ 'dir ve $\beta=0$ ve $d=1$ olduğunda model:

$$
\begin{aligned}
& \Delta y_{t}=\beta y_{t-1}+\tilde{\varphi} y_{t-1}\left(1-\exp \left\{-\gamma y^{2}{ }_{t-d}\right\}\right)+\varepsilon_{t} \\
& \Delta y_{t}=\varphi y_{t-1}\left(1-\exp \left\{-\gamma y_{t-d}^{2}\right\}+\varepsilon_{t}\right.
\end{aligned}
$$


$\varepsilon_{t} \sim \operatorname{iid}\left(0, \sigma^{2}\right)$

$\left(H_{0}: \gamma_{1}=0\right),\left(H_{1}: \gamma>0\right)$ test edilmektedir. Sıfır hipotezi altında $\gamma$ tanımlı olmadığı için Kapetanios vd. (2003) Taylor yaklaşımı ile aşağıdaki denklemi elde etmişlerdir.

$$
\Delta y_{t}=\delta y_{t-1}^{3}+\eta_{t}
$$

$H_{0}: \delta=0 H_{1}: \delta<0$ 'a karşı sınanmaktadır.

\section{Uygulama}

Çalışmada 1961-2017 yılları büyüme verileri (g ile gösterilmiştir) Dünya Bankası'ndan alınmıştır. Şekil 1 büyüme serisinin durağanlı̆ı̆ı göstermektedir. Ayrıca birim kök testi de yapılmıştır. Doğrusal ve doğrusal olmayan birim kök testlerine göre seri durağan bulunmuştur (Tablo 1 ve Tablo 2). Model için uygun gecikme uzunluğu Akaike bilgi kriterine göre iki bulunmuştur. Daha sonra modelin doğrusal olma durumu doğrusal olmama alternatifine göre test edilmiştir. Modelde farklı geçiş değişkenleri değerlendirilmiş ve birinci gecikme uygun geçiş değişkeni olarak seçilmiştir.

Şekil 1. Büyüme Serisi Grafiği

G

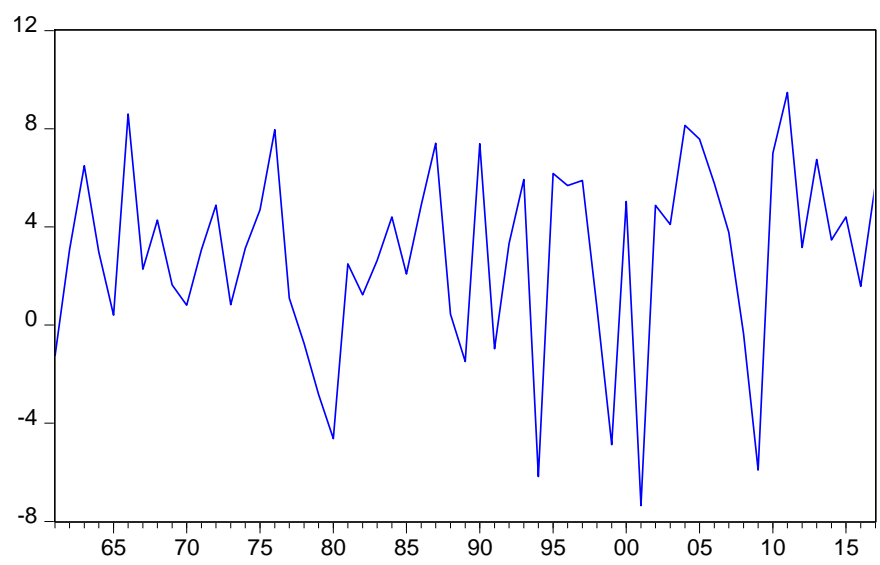

Tablo 1. Doğrusal Birim Kök Testi

\begin{tabular}{|c|c|c|c|}
\hline Değişken & Birim Kök Testi & Test İstatistiği & Olasılık Değeri \\
\hline g (sabitli model) & ADF & $-7,398379$ & 0,0000 \\
\hline $\begin{array}{c}\text { g (sabit+trendli } \\
\text { model) }\end{array}$ & ADF & $-7,366788$ & 0,0000 \\
\hline
\end{tabular}

\%1, \%5 ve \%10 anlamlılık düzeyinde sabitli model için tablo değerleri sırasıyla $-3,552666,-2,914517,-2,595033$ 'tür. \%1, \%5 ve \%10 anlamlılık düzeyinde sabit+trendli model için tablo değerleri sırasıyla $-4,130526,-3,492149,-3,174802$ 'dir.

Tablo 2. Doğrusal Olmayan Birim Kök Testi

\begin{tabular}{|c|c|c|}
\hline Değişken & Birim Kök Testi & Test İstatistiği \\
\hline $\mathrm{g}$ & $K S S_{c}$ & $-5,26$ \\
\hline $\mathrm{g}$ & $K S S_{t}$ & $-5,66$ \\
\hline
\end{tabular}

\%1, \%5 ve \%10 anlamlılık düzeyinde sabitten arındırılmış model için tablo değerleri sırasıyla $-3,48,-2,93,-2,66^{\prime}$ dır $\% 1, \% 5$ ve \%10 anlamlılık düzeyinde sabit ve trendden arındırılmış model için tablo değerleri sırasıyla $-3,93,-3,40,-3,13$ 'tür. 
Tablo 3. Doğrusallık Testi ve Uygun Model Tipi

\begin{tabular}{|c|c|c|c|c|c|}
\hline $\begin{array}{c}\text { Geçiş } \\
\text { Değişkeni }\end{array}$ & H0 & H01 & H02 & H03 & Model Tipi \\
\hline $\mathrm{g}(-1)$ & 0,0249 & 0,0171 & 0,0594 & 0,6149 & LSTAR \\
\hline
\end{tabular}

Tablo 3'e göre HO \%5 anlamlılık düzeyinde reddedildiği için model doğrusal değildir ve uygun model tipi LSTAR'dır. Tablo 4 ise doğrusal olmayan model tahminini göstermektedir. Buna göre de model (18) numaralı denklemde ifade edilmiştir.

Tablo 4. LSTAR Modeli Tahmin Sonuçları

\begin{tabular}{|c|c|c|c|c|}
\hline Değişkenler & Katsayı & Standart Hata & t ist & Olasılık değeri \\
\hline \multicolumn{5}{|c|}{ Doğrusal kısım } \\
\hline $\mathrm{g}(-1)$ & $-1,080475$ & 0,100520 & $-10,74885$ & 0,0000 \\
\hline $\mathrm{g}(-2)$ & $-0,307169$ & 0,208111 & $-1,475986$ & 0,1463 \\
\hline \multicolumn{5}{|c|}{ Doğrusal olmayan kısım } \\
\hline $\mathrm{g}(-1)$ & 1,586079 & 0,205046 & 7,735237 & 0,0000 \\
\hline $\mathrm{g}(-2)$ & 0,410979 & 0,245912 & 1,671243 & 0,1010 \\
\hline $\mathbf{r}$ & $\mathbf{9 0 . 3 1 8 8 7}$ & $\mathbf{0 , 0 2 2 3 3 9}$ & $\mathbf{- 5 2 , 9 2 8 4 6}$ & $\mathbf{0 , 0 0 0 0}$ \\
\hline $\mathbf{c}$ & $\mathbf{- 1 , 1 8 2 3 5 1}$ & Tanıs & \\
\hline \multicolumn{5}{|c|}{$\begin{array}{c}\text { Breusch-Godfrey (1): 0,2287 } \\
\text { ARCH (1): 0,2824 } \\
\text { Kalan Doğrusal Olmama Testi: 0,7180 } \\
\text { Parametre Sabitliği: 0,9607 }\end{array}$} \\
\hline
\end{tabular}

$$
g_{t}=-1.08 g_{t-1}-0.31 g_{t-2}+\left(1.59 g_{t-1}+0.41 g_{t-2}\right) x\left[1+\exp \left\{-90.32\left(g_{t-1}+1.18\right)\right\}\right]^{-1}
$$

Şekil 2. Geçiş Fonksiyonu

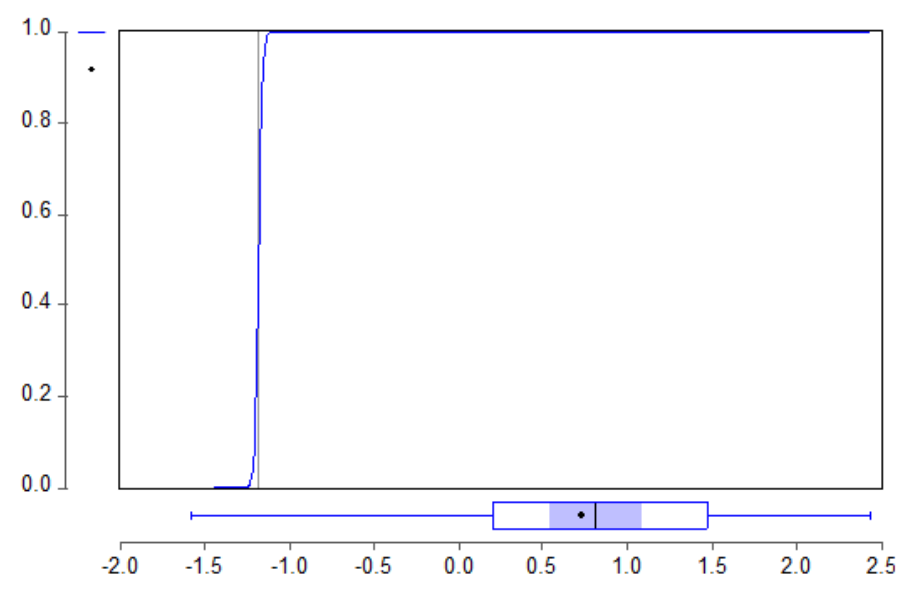

Terasvirta (1994) çalışması referans alınarak $\gamma$ ve c geçiş değişkeninin standart hatasına bölünerek ölçekten bağımsız hale getirilmiştir. Eşik değeri yıllık -\%1,2 olarak bulunmuştur. Büyümenin bu eşiğin altında ya da üstünde olmasına bağı olarak rejimler arasındaki geçiş hızıı (geçiş hızını gösteren parametre 90'dır) olmaktadır. Daha önce belirtildiği gibi $\gamma$ 'nın istatistiksel olarak anlamsız olması veri yaratım sürecini yakalayamadığı anlamına gelmemektedir. Özellikle de değeri büyükse böyle bir durumla karşılaşmak 
mümkündür. Neden olarak geçiş eşiğinin yakın komşuluğunda çok fazla gözlenen değer olmaması ifade edilmektedir (Bates ve \&Watts, 1988; Van Dijk vd., 2002). $\gamma^{\prime}$ nın standart hatası bu nedenle tabloda eklenmemiştir. Modelin yeterliliği de ayrıca test edilmiştir. Tanısal testler otokorelasyon ve değişen varyans probleminin olmadığını göstermektedir. Kalan doğrusal olmama testinde LSTAR modeli yeterli bulunmuş ve parametre sabitliği de sağlanmıştır. Geçiş fonksiyonunun yapısı Şekil 2'de görülmektedir. Daha önce yapılan çalışmalardan BouAli vd. (2016) $\gamma^{\prime}$ ’ın değerini yüksek bulmuşlardır. İngiltere için bazı makroekonomik serilerin asimetrik davranışlar gösterip göstermediğini inceleyen Öcal (2000) da GSYiH büyüme hızı için $\gamma^{\prime} n ı n$ değerini oldukça yüksek bulmuştur.

\section{Sonuç}

Pek çok iktisatçının da belirttiği gibi iktisadi zaman serilerinin büyük kısmı asimetrik davranışlar sergilemektedir. Doğrusal olmayan modellerin tahmin edilmesinde karşılaşılan güçlüklerden dolayı uzunca bir süre seriler doğrusal kabul edilip, tahminler buna göre gerçekleştirilmiştir. İleri ekonometrik programların geliştirilmesiyle son yıllarda zaman serisi analizinde doğrusal olmayan modellere olan ilgi daha da artmıştır. Bu modellere Markov rejim değişim modelleri, TAR ve STAR modelleri örnek gösterilebilir.

STAR modeli lojistik ve üssel modelleri ile asimetrik davranışları açıklayabilecek esnek yapıdadır. Rejimler arası geçişin yumuşak olduğu ifade edilse de, rejimler arası geçiş sert/hızlı olduğunda da gücünü kaybetmemektedir. Bu nedenle STAR modeli rejimler arası geçişin sert olduğu TAR modelinin genel bir halidir (Karaduman, 2007: 81).

Büyüme iktisatta önemli bir olgudur ve gelişmişliğin bir ölçüsüdür. Literatürde pek çok çalışmaya da konu olmuştur. Bu çalışmada da 1961-2017 yılları arasında Türkiye için kişi başına GSYiH büyüme hızının doğrusal yapıya sahip olup olmadı̆̆ının tahmin edilmesi amaçlanmıştır. Çalışmada STAR modellemesine yer verilmiştir. Doğrusallık hipotezi reddedilmiş ve uygun model LSTAR olarak bulunmuştur. Bulgular bir rejimden diğerine geçişin hızlı olduğunu göstermektedir. Bu yıllar arasında yaşanan ekonomik krizler ve konjonktürün bu duruma neden olduğu söylenebilir. Genel olarak doğrusal olmama iktisadi olarak iş çevrimlerindeki asimetriye, ani artış ve azalışlara işaret etmektedir. Bu çalışmanın literatürdeki diğer çalışmalardan farkı Türkiye için büyümeyi geniş bir dönem için STAR modelleri ile incelemesidir. Daha önceki çalışmalardan Akgül ve Özdemir (2012) 2003-2009 dönemi enflasyon büyüme ilişkisini TAR modeli, Karaduman (2007) 1980-2006 dönemi enflasyon büyüme ilişkisini STAR modeli ile incelemişlerdir.

Geçiş hızının yumuşak ya da sert olması konusunda "Tedrici" ve "Soğuk Hindi" yaklaşımlarını incelemekte fayda vardır. Tedrici yaklaşımda yavaş ve istikrarlı düşük enflasyon hedeflenmiştir. Para arzı artış oranında yavaş kesintilerle başlar ve toplam talep eğrisi ile kısa dönemli arz eğrisini aşağı kaydırır. Para arzındaki artışlar kademeli bir şekilde azaltılır ve süreç devam eder (Dornbusch ve Fischer, 1994: 544). Soğuk Hindi stratejisi enflasyon oranını hızlı bir şekilde kesmeyi hedeflemiştir. Para arzındaki keskin bir düşüşle başlar ve toplam talep eğrisini kaydırır. Enflasyon oranındaki büyük bir düşüş ile kısa dönemli arz eğrisini de hızlıca aşağı kaydııır. Para arzındaki artış oranını düşük tutarak baskıya devam eder. Sonuçta enflasyon oranı hızlıca düşer ve çıktı ile istihdam tekrar büyümeye başlar (Dornbusch ve Fischer, 1994: 545). Bu bağlamda Tedrici yaklaşım yumuşak geçişi, Soğuk Hindi yaklaşımı ise sert geçişi göstermektedir. Yüksek enflasyonun büyüme üzerinde negatif, düşük enflasyonun ise büyüme üzerinde pozitif etkisi olduğu literatürdeki pek çok çalışmada da ifade edilmiştir. Uygulanacak ani bir politikanın da büyüme üzerinde hızlı geçişlere neden olacağı söylenebilir.

\section{Kaynaklar}

Akgül, l., \& Özdemir, S. (2012). Enflasyon eşiği ve ekonomik büyümeye etkisi. iktisat iş̧letme ve Finans, 27(313), 85-106.

Andrzejak, R. G. (2011). Nonlinear time series analysis in a nutshell, Osorio et al. (eds.) Epilepsy: The Intersection of Neurosciences, Biology, Mathematics, Engineering and Physics.

Bates, D. M., \& Watts, D. G. (1988). Nonlinear regression and its applications. New York: John Wiley. 
Bayramoğlu Tay, A., \& Yurtkur Koç, A. (2016). Türkiye'de karbon emisyonu ve ekonomik büyüme ilişkisi: Doğrusal olmayan eşbütünleşme analizi. АіВÜ Sosyal Bilimler Enstitüsü Dergisi, 16(4), 31-45.

Bildirici, M. E., Aykaç Alp, E., Ersin, Ö. Ö., \& Bozoklu, Ü. (2010). Iktisatta kullanılan doğrusal olmayan zaman serisi yöntemleri. Türkmen Kitabevi.

BouAli, M., Nasr, A. B., \& Trabelsi, A. (2016). A nonlinear approach for modeling and forecasting US business cycles. International Economic Journal, 30(1), 39-74.

Burren, D., \& Neusser, K. (2010). The decline in volatility of US GDP growth. Applied Economics Letters, 17(16), 16251631.

Camarero, M., \& Ordonez, J. (2012). Nonlinear adjustment in the real dollar-euro exchange rate: The role of the productivity differential as a fundamental. Economic Modelling, 29, 444-449.

Dornbusch, R., \& Fischer, S. (1994). Macro economics (Sixth Ed.). McGraw-Hill, Inc.

Eitrheim, $\varnothing$., \& Terasvirta, T. (1996). Testing the adequacy of smooth transition autoregressive models. Journal of Econometrics, 74, 59-75.

Fiaschi, D., \& Lavezzi, A.M. (2003). Distribution dynamics and nonlinear growth. Journal of Economic Growth, 8, 379401.

Fiaschi, D., \& Lavezzi, A. M. (2007). Nonlinear economic growth: Some theory and crosscountry evidence. Journal of Development Economics, 84, 271-290.

Florax, R. J. G. M., Pede, V. O., \& Holt, M. T. (2009). Spatial econometric Star model, working paper. Available online at: http : //www.ub.edu/sea2009.com/P apers/167.pdf.

Granger, C. W. J., \& Terasvirta, T. (1993). Modelling nonlinear economic relationships. Oxford: Oxford University Press.

Hamilton, J. D. (1987). A new approach to the economic analysis of nonstationary time series and the business cycles. Econometrica, 57(2), 357-384.

Kalaitzidakis, P., Mamuneas, T., Savvides, A., \& Stengos, T. (2001). Measures of human capital and nonlinearities in economic growth. Journal of Economic Growth, 6, 229-254.

Karaduman, H. A. (2007). İktisatta doğrusal olmayan zaman serisi modelleri: Kuram ve Türkiye uygulaması. Yıldız Teknik Üniversitesi Sosyal Bilimler Enstitüsü, Doktora Tezi, İstanbul.

Kunitomo, N., \& Sato, S. (1996). Asymmetry in economic time series and the simultaneous switching autoregressive model. Structural Change and Economic Dynamics, 7, 1-34.

Luukkonen, R., Saikkonen, P., \& Terasvirta, T. (1988). Testing linearity against smooth transition autoregressive models. Biometrika, 75, 491-499.

Mills, C. T. (1995). Business cycle asymmetries and nonlinearities in U.K. macroeconomic time series. Ricerche Economiche, 49, 97-124.

Neftçi, S. N. (1984). Are economic time series asymmetric over the business cycles. Journal of Political Economy, 92, 307-328.

Nejad, H. A., Motavasseli, M., \& Mohammadi, S. (2005). economic growth as a nonlinear and discontinuous process. Econometrics 0510008, University Library of Munich, Germany.

Öcal, N. (2000). Nonlinear models for UK macroeconomic time series. Studies in Nonlinear Dynamics and Econometrics, 4, 123-35.

Öcal, N. (2006). Nonlinear models, composite longer leading indicator and forecasts for UK real GDP. Applied Economics, 38, 1049-53.

Parasız, i. (2008). Ekonomik büyüme teorileri. Bursa: Ezgi Kitabevi.

Pede, O., Florax, J. G. M., \& Holt, T. (2008). Modeling nonlinear spatial dynamics: A family of spatial STAR models and an application to U.S. economic gGrowth. 2008 Annual Meeting, July 27-29, 2008, Orlando, Florida 6518, American Agricultural Economics Association.

Peretto, P. F. (1999). Industrial development, technological change, and long-run growth. Journal of Development Economics, 59, 389-417.

Potter, S. M. (1993). A nonlinear approach to U.S. GNP. UCLA Economics Working Papers 693, UCLA Department of Economics.

Rostow, W. W. (1960). The stages of economic growth. Oxford: Oxford University Press. 
Schein, A. (2013). Growth in per Capita GDP in the West Bank and Gaza 1950-2005. Middle Eastern Studies, 49(6), 973989.

Terasvirta, T. (1994). Specification, estimation and evaluation of smooth transition autoregressive models. Journal of the American Statistical Association, 89, 208-218.

Terasvirta, T., \& Anderson, H. M. (1992). Characterizing nonlinearities in business cycles using Star models. Journal of Applied Econometrics, 7, 119-136.

Van Dijk, D., Terasvirta, T., \& Franses, P. H. (2002). Smooth transition autoregressive models: A survey of recent developments. Econometric Reviews, 21, 1-47.

https://data.worldbank.org/ 